\title{
ONLINE LEARNING AND HIGH SCHOOL STUDENTS: A CULTURAL PERSPECTIVE
}

\author{
Dr. Salih BARDAKCI \\ Computer Education \& Instructional Technologies \\ Tokat Gaziosmanpasa University \\ Tokat, Turkey \\ Omer ARSLAN \\ Instructional Systems \& Learning Technologies \\ Florida State University \\ Tallahassee, USA \\ Yafes CAN \\ Department of Curriculum and Instruction \\ Anadolu University \\ Eskisehir, Turkey
}

\section{ABSTRACT}

The purpose of this study is to investigate the insights of high school students regarding their online learning experiences in the margin of cultural considerations. The study was designed in a qualitative pattern. The data were collected through a questionnaire including eight open ended questions along with demographics. A total of $\mathbf{3 0}$ high school students enrolled in an online learning environment participated in this study. The findings revealed that the majority of the students benefited from online discussion activities, as well as posed numerous suggestions. They found it safe to express their opinions due to the feeling of peer and teacher presence. Students reported that one of the primary boundaries was the lack of self-confidence to share and the visibility of their postings by the others. When compared to in-classroom discussion activities, online discussions were found to be more flexible for sharing ideas freely without any pressure. Implications were discussed for further research.

Keywords: Online learning, high school students, culture, qualitative study.

\section{INTRODUCTION}

There is a widespread adoption of online learning across the globe to complement "bricks and mortar" manner of education (Selwyn, 2016). McDermott (2017) stated that appropriate pedagogical approaches and technology are forefront excluding cultural dynamics during the operationalization of online learning. In fact, there are two main considerations for the acceptance and use of technology, one of which is technological and the other one is socio-cultural factors (Venkatesh, Thong, \& Xu, 2016). On one hand, technological factors might provide both student and teachers with diverse opportunities. For instance, online learning might facilitate students with the opportunity of self-paced learning, access to floating of information over the internet or the flexibility of "anytime anyplace any pace" learning (Lecluijze, de Haan, \& Ünlüsoy, 2015). Meanwhile, teachers may extend their potential to teach, share materials at a lower cost or contact with students more easily (Jayatilleke \& Gunawardena, 2016; Selwyn, 2016). There is no doubt that technological factors might play a prominent role for the widespread adoption of online learning due to its inherent affordances. On the other hand, cultural factors may also 
intervene in the operationalization of online learning as learning benefits could not be separated from one's own social and cultural complex space (Boeri, 2016). For instance, students' and teachers' cultural backgrounds with respect to various dimensions as proposed by Hofstede (1986), such as, power distance, individualism/collectivism, masculinity/femininity or uncertainty avoidance, might play an important role on how teaching-learning processes are carried out. With this in mind, it gains importance to reveal how both technological and / or socio-cultural factors might facilitate an improved state of students' learning along with a more effective teaching-learning practices. Although the inherent affordances of technological factors are not deniable altogether and essentially important to be investigated, the primary concern of this study is how cultural considerations might be associated with online learning environments. From this view, the purpose of this study is to investigate the insights of high school students enrolled in an online learning environment in the margin of cultural dimensions proposed by Hofstede (1986).

\section{LITERATURE REVIEW}

\section{Culture and Pedagogical Assumptions}

Previous studies report that there is an association between cultural background, learning styles, and cognitive processing (Joy \& Kolb, 2009; Sanchez \& Gunawardena, 1998). From this view, a body of literature focusing on pedagogical assumptions with respect to cultural differences, particularly presumptions attributed to students and teachers, suggest that there might be variations within different cultural backgrounds, such as Western and nonWestern cultures. For instance, Frisby, Slone, and Bengu (2016) investigated studentinstructor rapport with college students from the United States of America (USA) and Turkey. The researchers found that there is a statistically significant difference in rapport between the two samples with Turkish students reporting significantly less rapport with the instructors. The researchers discussed this finding with respect to differing cultural background in these two countries. They stated that Turkey has a large power distance culture compared to USA and students may see their instructors as authoritarian and attribute higher positions in the hierarchy that makes interpersonal relationships less appropriate. Kang and Chang (2016) stated that there are three core education beliefs that distinguish students in Confucian culture from their Western peers. First, students in Confucian culture are not generally comfortable in challenging their teacher and stands on the receptive side of learning. Second, conflict is not acquired as a desirable act and should be avoided. Third, students' academic achievement and success is stressed rather than having fun or excitement with learning experiences. The researchers associated variations in pedagogical assumptions with Hofstede's cultural dimensions' theory. Baran (2010) carried out a study with undergraduate students on the use of Facebook as a formal application to support classroom activities. The study revealed that by the end of the term, only half of the students added their instructor to their profile due to the assumption that "teachers should be unapproachable and formal" (p. E147). The researcher justified this finding with Turkey's large power distance background. Zhang (2007) stated that Eastern cultural tradition has a group-based, teacher-dominated, and centrally organized pedagogical culture in which learners are fully respectful to knowledge and teachers, strengthens orders and disciplines, official teachers' guide direct the content for teaching, and education is seen as a way to establish higher social statuses which are at the opposite spectrum of Western pedagogy. The existing literature on culture and pedagogical assumptions reveal that the two phenomenon are strictly bounded to each other. In fact, the existing literature emphasize that pedagogical assumptions and presumptions attributed to students and teachers have an influence on how teaching and learning processes are being carried out (e.g. Chen \& Bennett, 2012; Mansson \& Lee, 2014; Zhang, 2007). At this point, how culture is defined and associated with educational practices is important to be clarified within the context of Turkey.

\section{Turkey in Hofstede's Cultural Dimensions Theory}

According to Vatrapu and Suthers (2007) culture is a concept that has a checkered intellectual history. There are numerous conceptualizations concerning what culture is. For 
instance, Dennehy (2015, p. 823) conceptualized national culture as "shared assumptions, values and behavior at a national level." Although there is a wide variety of definitions, Geert Hofstede's definition of culture is still influential in contemporary cultural studies. It is defined as "the collective programming of the mind that distinguishes the members of one group or category of people from others" (Hofstede, Hofstede, \& Minkov, 2010, p. 6).

According to Hofstede (1983) societies face with fundamental problems and they differ with respect to answers to those problems. To this end, a study was conducted involving 116,000 questionnaires, 50 countries and 3 regions. Participants from Turkey were also included and the results with respect to four cultural dimensions were reported, as well. Two more cultural dimensions were added to the theory during further studies. Figure 1 illustrates the six cultural dimensions and indexes for Turkey.

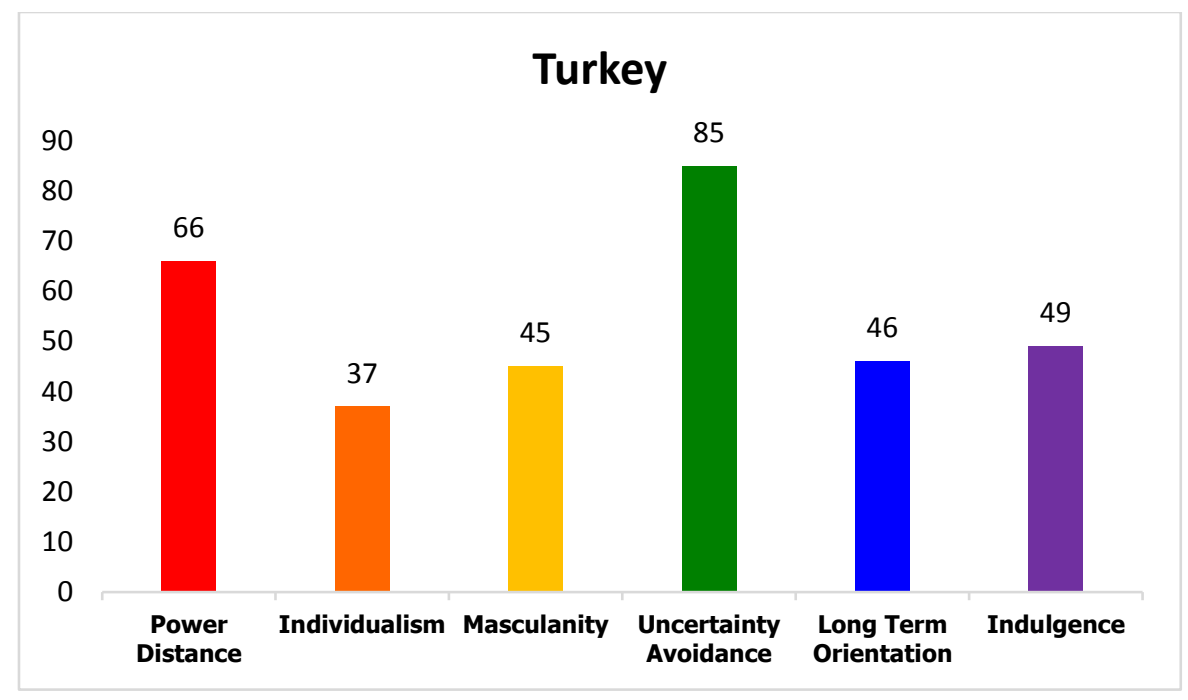

Figure 1. Cultural Dimensions and Turkey's Indexes

There are six cultural dimensions including power distance, individualism/collectivism, masculinity/femininity, uncertainty avoidance, long/short term orientation, and indulgence/restraint. First, as it is illustrated in Figure 1, Turkey has a large power distance index. Power distance is defined as "the extent to which the less powerful members of institutions and organizations within a country expect and accept that power is distributed unequally" (Hofstede et al., 2010, p. 61). Power distance is about the idea that in a society people are not equal due to unequal distribution of power amongst those people. For instance, take the case of student-teacher interaction. Since teachers generally have more power and authority with respect to students, there is an unequal distribution of power which leads to accepted and expected patterns of behavior. According to Hofstede (1986) there are numerous implications of large power distance cultural background amongst how students and teachers interact. Examples include but not limited to teacher centered pedagogy, teachers as authority figures never contradicted nor publicly criticized, and teachers meriting the respect of her/his students. On the other hand, students in large power distance society speak up in class only when invited by the teachers or they expect their teachers to initiate the communication. This implies that as having a high index of power distance cultural dimension, both students and teachers in Turkey would tend to have those cultural patterns during student teacher interaction. Second, from Figure 1 it is seen that individualism index is low. This shows that Turkey generally stands on the collective side of the spectrum. Hofstede et al. (2010, p. 92) defined collectivism as "societies in which people from birth onward are integrated into strong, cohesive ingroups, which throughout people's lifetime continue to protect them in exchange for unquestioning loyalty." Collectivism as one of the cultural dimensions has also numerous influences on student teacher interaction. For instance, in collectivist societies face gaining is a major issue both for students and teachers, formal harmony should be maintained by each stakeholder, certificates are forefront rather than acquiring related competence. 
Students in a collectivist culture tend to refrain from speaking up in larger groups without a teacher present, particularly in case of an existence of out-group members. Furthermore, rather than treating each and every student as an isolated individual, teachers in collectivist societies are expected to deal with them as part of an in-group. The third cultural dimension is masculinity/femininity in which Turkey's index is 45, implying that it is closer to feminine cultural background. Hofstede et al. (2010, p. 140) conceptualized feminine society "when emotional gender roles overlap, both men and women are supposed to be modest, tender, and concerned with the quality of life." There are numerous differences between masculine and feminine cultures with respect to student teacher interaction along with roles attributed to them. In feminine societies, for instance, praising students openly is avoided by teachers and average student is accepted and expected to be the norm by teachers. Moreover, students' social adaptation skills, teachers' friendliness, effective student-teacher relationships and proximity between the two are amongst the primary drivers during student-teacher interaction (e.g. Çetin, Ellidokuzoglu, $\&$ Dogan, 2014). Fourth, Turkey's uncertainty index is 85 , which is very high. Hofstede et al. (2010, p. 191) defined uncertainty avoidance as the "the extent to which the members of a culture feel threatened by ambiguous or unknown situations." According to Hofstede (1986) there are numerous implications of high uncertainty avoidance in learning environment. For instance, students feel more comfortable in a structured learning environment in which strict timetables are forefront, detailed assignments are prospected, and objectives are precisely reported. On the other hand, teachers are expected to have all the answers with respect to academic domain, and they generally use academic language. While the cultural dimensions theory is based on empirical data and illustrates comprehensive framework to study cultural considerations across the globe, there are also some critics concerning its applicability to the complex nature of human interaction. One of the primary issues is about the sample used to collect the data; that is, IBM workers. In this regard, researchers caution about its applicability and validity with respect to other groups one of which is students and teachers. Another consideration that should be taken into account is that it underpins nation as a unit of analysis rather than individual which raises doubts concerning the ecological validity even though it is reported that this objection does not have empirical support (Minkov \& Hofstede, 2012). Even though this theory posits numerous thresholds, it also opens up new avenues to test whether it is applicable or not with different participants, settings, and cultural niches. In this regard, this study underpinned Hofstede's (1986) cultural dimensions theory. By citing Cronje (2011) the primary purpose was to get students' voices to give deeper meanings to those cultural indexes.

\section{Culture and Online Learning}

There is a growing body of literature emphasizing the value and importance of how cultural dimensions might influence teaching-learning processes in online learning environments. The operationalization of online learning is classified within three categories with respect to cultural perspectives (Al-Harti, 2005). Studies being operationalized within a certain culture (e.g. Hamdan, 2014), intercultural studies with individuals from different cultural units in a certain culture (e.g. Lecluijze et al., 2015; Sadykova, 2014; Zhang, 2013; Zhang \& Kenny, 2010), and cross-cultural studies where individuals are compared with different cultural units (e.g. Commander, Zhao, Gallagher, \& You, 2016; Dennehy, 2015). For instance, in a study carried out within a certain cultural setting in Saudi Arabia, Hamdan (2014) found that both students' learning cultures and the culture of online learning have reciprocal influences on each other. In an intercultural online learning study, Zhang (2013) studied with students from Confucian-heritage culture in the USA. The researcher found that despite online learning environment was seen beneficial for students' engagement, they intimidated to contact with their instructors due to the fact that instructors' were attributed with high power. Liu, Liu, Lee, and Magjuka (2010) carried out a study with international students to gather their perceptions toward their online learning experience. They found that Eastern students were more likely to be modest, face saving and prefer group work, while U.S. students preferred being independent, assertive and confident. Although students reported that there were cultural differences, it did not affect their communication or collaboration negatively. Bing and Ping (2008) carried out a study to 
investigate whether cultural diversity of learners might influence their interaction behavior in the web-based learning environment. The study showed that learners from different national cultural backgrounds differed from each other with respect to their interaction patterns.

Although there is a growing body of studies investigating insights of the participants from different cultural backgrounds, Uzuner (2009) found that the majority of these studies tend to focus on Asian learners. Hence, it is suggested that researchers from diverse cultural backgrounds should carry out studies that will improve the currently limited understanding of cultural influences in online learning environments (Bozkurt et al., 2015; Wong, Zeng, \& Ho, 2016). From this view, this study investigated the insights and experiences of $\mathbf{3 0}$ high school students enrolled in an online learning environment, particularly by associating their insights with cultural dimensions proposed by Hofstede et al. (2010).

\section{RESEARCH METHOD}

This study is carried out in a qualitative pattern, particularly qualitative descriptive approach by drawing on deductive content analysis. Since there is a low level of interpretation of participants' specifications, qualitative descriptive approach was depicted (Vaismoradi, Turunen, \& Bondas, 2013). As Bloor and Wood (2006, p. 58) stated, deductive content analysis enabled researchers to associate participants' insights by reporting "who says what, to whom and with what effect." To this end, in an English Language course, insights of high school students enrolled in an online learning environment for 7 weeks were associated with cultural dimensions proposed by Hofstede (1986). To associate participants' insights with cultural dimensions, numerous questions were developed by the researchers based on an intense literature review. The qualitative questions developed by the researchers covered five themes and respective associations with cultural dimensions theory were derived from those five themes. Those themes are participants' experiences of online discussion activities, perceptions of self-expressing, perceptions of teacher, instructor and peer presence, factors stimulating or hindering participation, and differences between online and face-to-face discussion activities.

\section{Participants}

This study was conducted with $\mathbf{3 0}$ high school students as part of their English language classes during the academic year of 2016-2017. There were 18 female and 12 male students. The age of participants ranged from 16 to 18 years old. Twenty nine of them reported that they had a smart phone with internet connection. The online discussion activities were carried out on the basis of voluntary participation, there was no penalty or incentive for the participation. These students were in a class where they extensively study English as a foreign language. All of the students, the teacher and the instructor were from Turkey, implying that the study was carried out within a certain cultural context. For the purpose of this study, online learning is defined as "web based learning environments consisting of digitally formatted content resources via the use of the World Wide Web and communication devices to provide communication link between the instructor and students where they can actively interact" (as cited in Nandi, Hamilton, Chang, \& Balbo, 2012, p. 685).

\section{Setting}

The online learning experience lasted for seven weeks, while two of them were for ensuring technical appropriateness and online socialization, five of them were discussion activities. To ensure that all the students were qualified to experience online learning, Salmon's (2002) five-stage model for teaching and learning online was followed. Figure 2 illustrated the model and the processes underpinned in this study. 


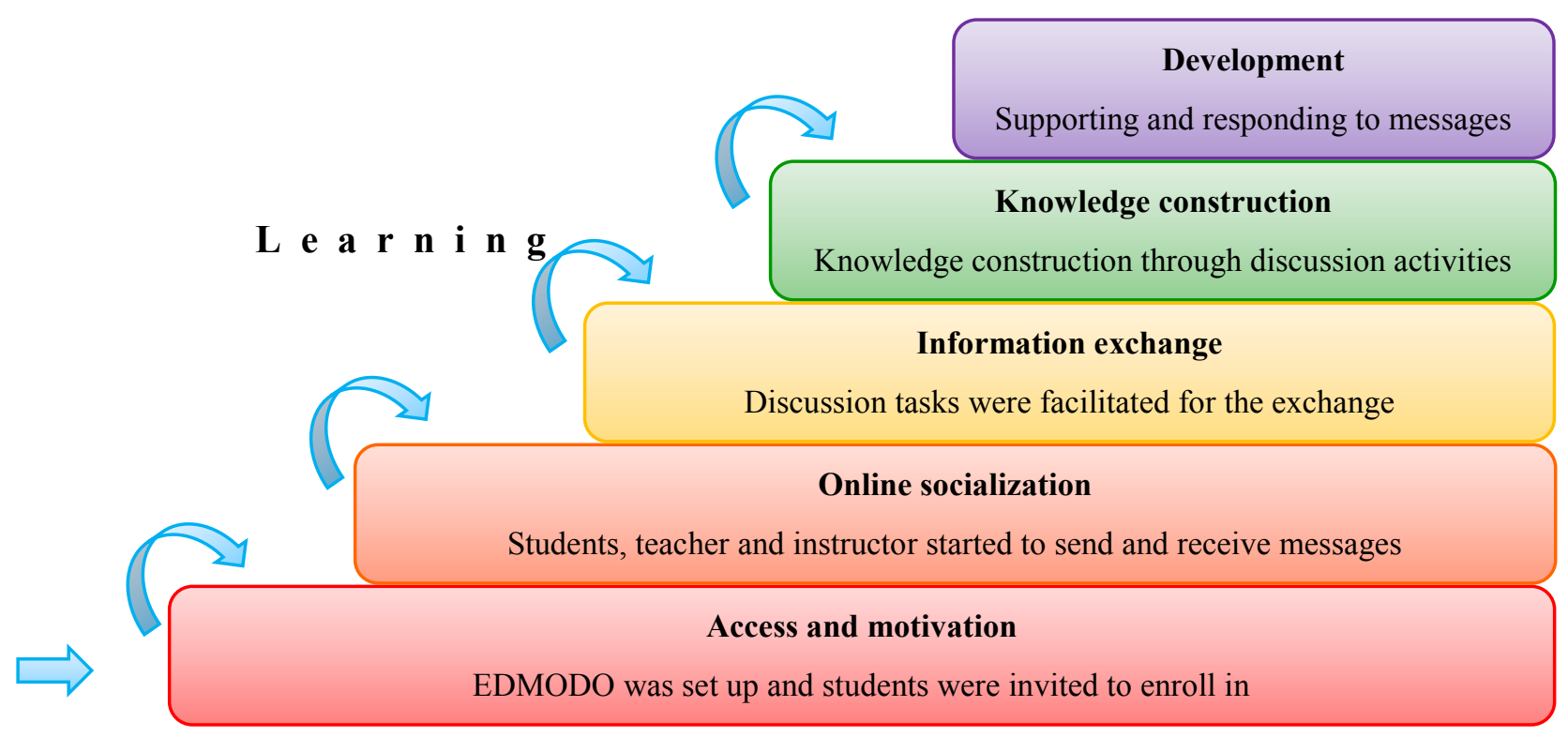

Figure 2. Model of Online Learning Activities

According to this model, there are five successive stages which are access and motivation, online socialization, information exchange, knowledge construction, and development. This model primarly focuses on how online learners might benefit from the online learning environment and how e-moderators could follow the successive stages. In light of this model, first, EDMODO, which is a free web based platform that enables students, teachers and parents to enrol in online learning environments, was chosen due to accessibilty considerations. After the researhers ensured that the content and technical considerations are appropriate, students were informed about the process during one of their classes. Students were informed that they will enrol in an online learning environment with their full names in which online discussion activities will be operationalized. After that, researchers prepared a short video with Screencast-O-Matic, which is a free application to capture monitor screen as video. This video demonstrated EDMODO, such as how they can register and enrol into the group defined for the English language course or how they might reply to each other. Second, after ensuring that students have access to the group, for the first activity as online socialization, they introduced themselves both for controlling whether they have problems with their postings and to meet with the instructor that they do not know and see before. Third, researchers degined five discussion sessions and shared it online. The primary purpose of these discussion sessions were to enable students experience the online learning environment and to get their insights.

\section{Quality of Online Interaction}

Based on the rubric developed by Roblyer and Wiencke (2003) to asses the quality of an interaction operationalized within distance courses, the researchers determined several interaction patterns in line with both students', teacher's and reserchers' capabilities for carrying out online discussion activities. There are five design elements to asses the interaction quality which are illustrated in Table 1 . There are three levels of interaction and interactivity of a course; which are low (1-9 points), moderate (10-17 points) and high (1825). The interactivity of online learning environment designed and operationalized in this study have 13 points from the rubric implying that the level of interaction and interactivity was moderate. 
Table 1. Interactive qualities of online learning environment

\begin{tabular}{|c|c|c|}
\hline Element \# & Qualities & Points \\
\hline $\begin{array}{l}1-\text { Social / } \\
\text { rapport building }\end{array}$ & $\begin{array}{l}\text { Students, teacher and instructor introduced themselves } \\
\text { and provided additional personal information with their } \\
\text { biographies. }\end{array}$ & 2 \\
\hline $\begin{array}{l}2 \text { - Instructional } \\
\text { design }\end{array}$ & $\begin{array}{l}\text { Discussion activities required students to communicate } \\
\text { both with the instructors and their peers. }\end{array}$ & 3 \\
\hline $\begin{array}{l}3 \text { - Interactivity } \\
\text { of technology } \\
\text { resources }\end{array}$ & $\begin{array}{l}\text { Students, teacher and instrcutor had a two-way, } \\
\text { asynchronous exchanges of information. }\end{array}$ & 2 \\
\hline $\begin{array}{l}4 \text { - Evidence of } \\
\text { learner } \\
\text { engagement }\end{array}$ & $\begin{array}{l}\text { Toward the end of discussion activities, most students } \\
(50 \%-75 \%) \text { were replying to and initiating posts when } \\
\text { required and voluntarily. }\end{array}$ & 4 \\
\hline $\begin{array}{l}5 \text { - Evidence of } \\
\text { instructor } \\
\text { engagement }\end{array}$ & $\begin{array}{l}\text { Instructors responded to most student queries; } \\
\text { responses usually are within } 48 \text { hours; feedback } \\
\text { sometimes offers some analysis of student work and } \\
\text { suggestions for improvement. }\end{array}$ & 2 \\
\hline
\end{tabular}

\section{Data Collection and Analysis}

The data of the study were collected by a qualitative questionnaire developed by the researchers. There were 8 open-ended questions, along with demographics (Appendix A). Although 31 students enrolled in online learning environment, the data were collected from 30 students after the completion of activities. During the data collection, students were informed to specify their thoughts as much detailed as possible.

Data were analyzed in a deductive qualitative content analysis approach. In this regard, the study followed and underpinned concepts, procedures and measures as suggested by Graneheim and Lundman (2004) which is illustrated in Figure 3. First, before analyzing the qualitative text data, participants' insights were read several times to gain a sense of the whole. At this point, the researchers presumed and realized that "a text always involves multiple meanings and there is always some degree of interpretation when approaching a text" (Graneheim \& Lundman, 2004, p. 106). With this in mind, along with focusing on the manifest content as it deals with the obvious aspects of the data rather than the hidden agendas (Bloor \& Wood, 2006), latent content was also taken into consideration in case it is necessary. Second, qualitative questionnaires including text data fulfilled by each participant was determined as the unit of analysis. Third, each qualitative text data under representative question was considered as a whole; in other words, as a meaning unit. Fourth, meaning units were condensed under representative cultural dimensions. Fifth, abstraction within the whole data was established through grouping them under representative cultural dimensions. Sixth, based on the theoretical framework and predetermined qualitative questions, three content area was identified; which are individualism/collectivism, power distance, and uncertainty avoidance. Seventh, participants' insights were assigned with codes, but the primary aim of this study was not to reach a whole picture about the distribution of frequencies and percentages of those codes. In this regard, just a few examples were illustrated in Table 2 to provide an insight concerning the procedure of data analysis. 


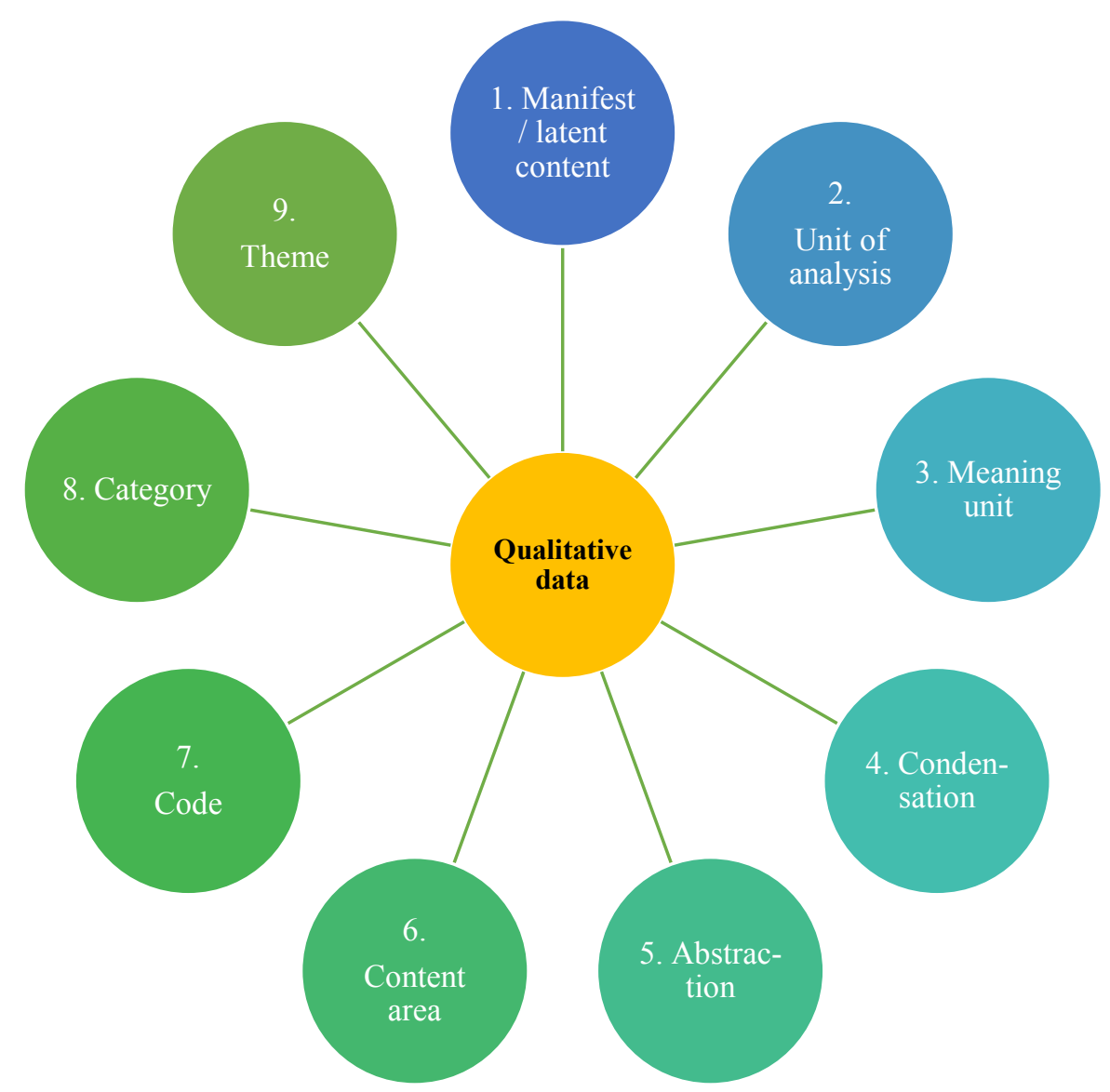

Figure 3. Concepts used during qualitative data analysis

Table 2. Several Examples for the Analysis of the Qualitative Text Data

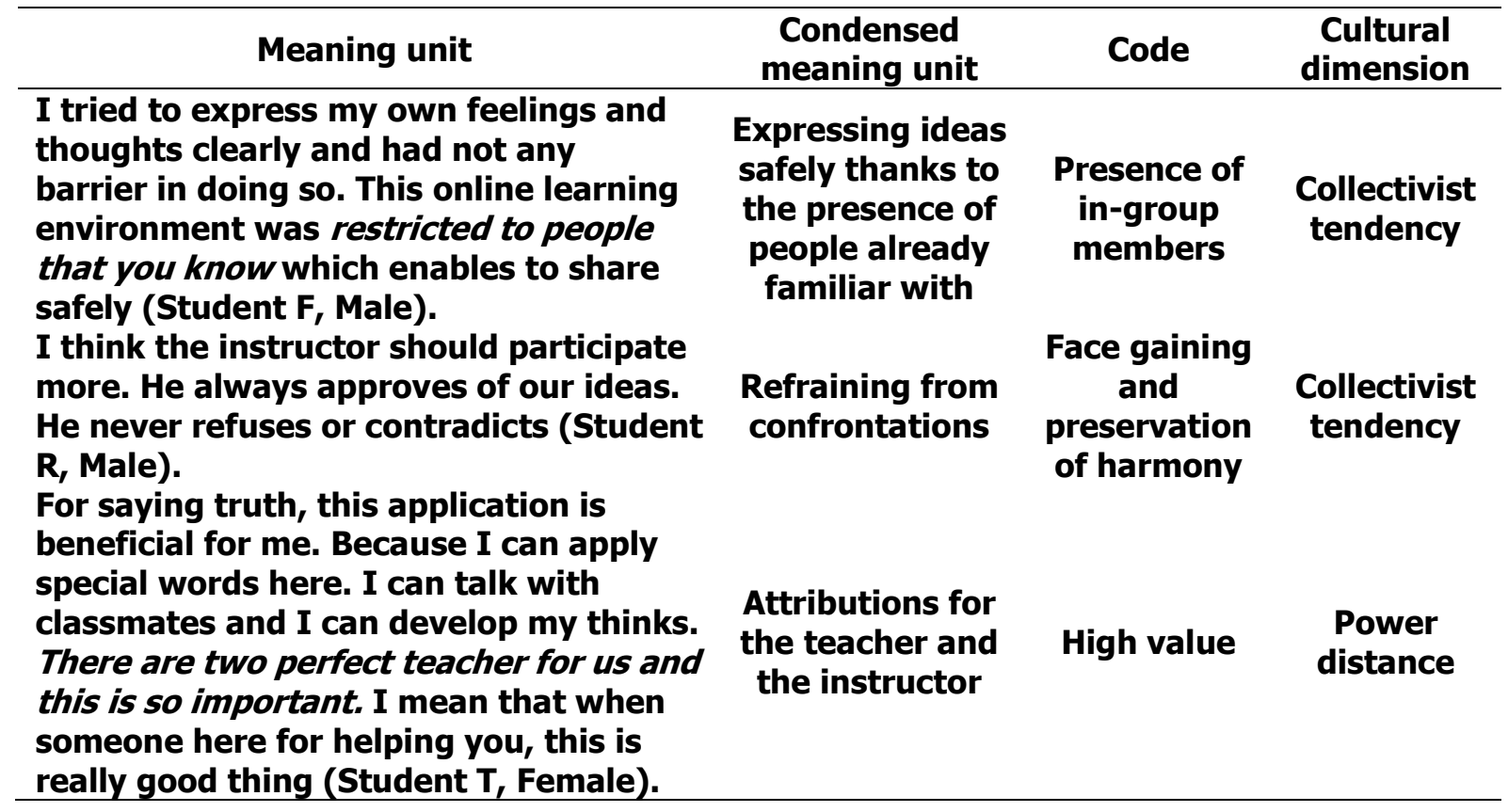


In classroom setting where we are constantly gazed, not confident enough to express our thoughts fully is different from online activities which enabled me to participate in at home by voicing my inner and deeper thoughts without the pressure of outer voices (Student S, Female).

Initially, I struggled to share my opinions in online learning environment. Later on I realized that I can post my thoughts in which my peers and my teacher helped me. I recognized an online learning environment where we can brainstorm. I had no difficulty or problems concerning security issues as I enrolled (Student B, Female).
Not confident for expressing ideas due to pressure

High power

Power

distance

Validity of the Qualitative Questionnaire

The validity of the qualitative questionnaire was satisfied by getting expert views with a form. There were 8 questions and five experts provided feedback; three of which were from the field of education, and the two of them were from curriculum and instruction. There were three aspects to fulfill which are content validity, the appropriateness of language and meaning for the target participants, and feedback for each question, if necessary. The directions and feedback gathered enabled researchers to further refinement. After minor revisions gathered from the experts, the final version of the qualitative questions were completed.

The reliability of the qualitative questionnaire could not be explored due to the limitation of reaching participants experienced online learning at high school level. Hence, although researchers' experiences in carrying out studies in online learning environments and experts' views provide a level for validity, establishing the reliability of the qualitative questionnaire might be stated as one of the limitations of this study.

\section{Limitations}

The study was carried out in a qualitative pattern and investigated insights of high school students enrolled in an online learning environment. First, as Fraenkel and Wallen (2006) argued, in qualitative research collecting and interpreting data is so dependent on the researchers that the consideration of researcher bias should be taken into account for evaluating the findings. Second, the participants were acknowledged with respect to national cultural backgrounds, rather than individual tendencies in which there might be a fallacy of homogeneity (Uzuner, 2009). Third, the discussion activities were carried out in English. Although students were in English language class and extensively exposed to English as a foreign language, students having language difficulties might not be attracted as much as those having higher levels of proficiency. Fourth, the data of the study were collected by students' English language teacher in one of their courses by self-report measure in which there might be an extent of social desirability bias. And finally, by citing Chen and Bennett (2012, p. 690) these limitations "do not discount the possibility that other factors above and beyond the scope of this study may also have played a role."

\section{FINDINGS}

The findings show that students generally have positive perceptions and benefitted from online learning environment, along with proposing implications for further refinement. The analysis showed that there are five themes including their experiences of online discussion activities, perceptions of self-expressing, perceptions of teacher, instructor and peer presence, factors stimulating or hindering participation, and differences between online 
and face-to-face discussion activities. Figure 4 illustrates participants' insights and respective cultural considerations. Supporting quotes were illustrated with respect to each theme as derived in light of qualitative questions.

- More comfortable to voice up the minds in online learning possibly due to lessened power asymmetries

- More teacher/instructor presence was expected

- High value for teacher/instructor comments

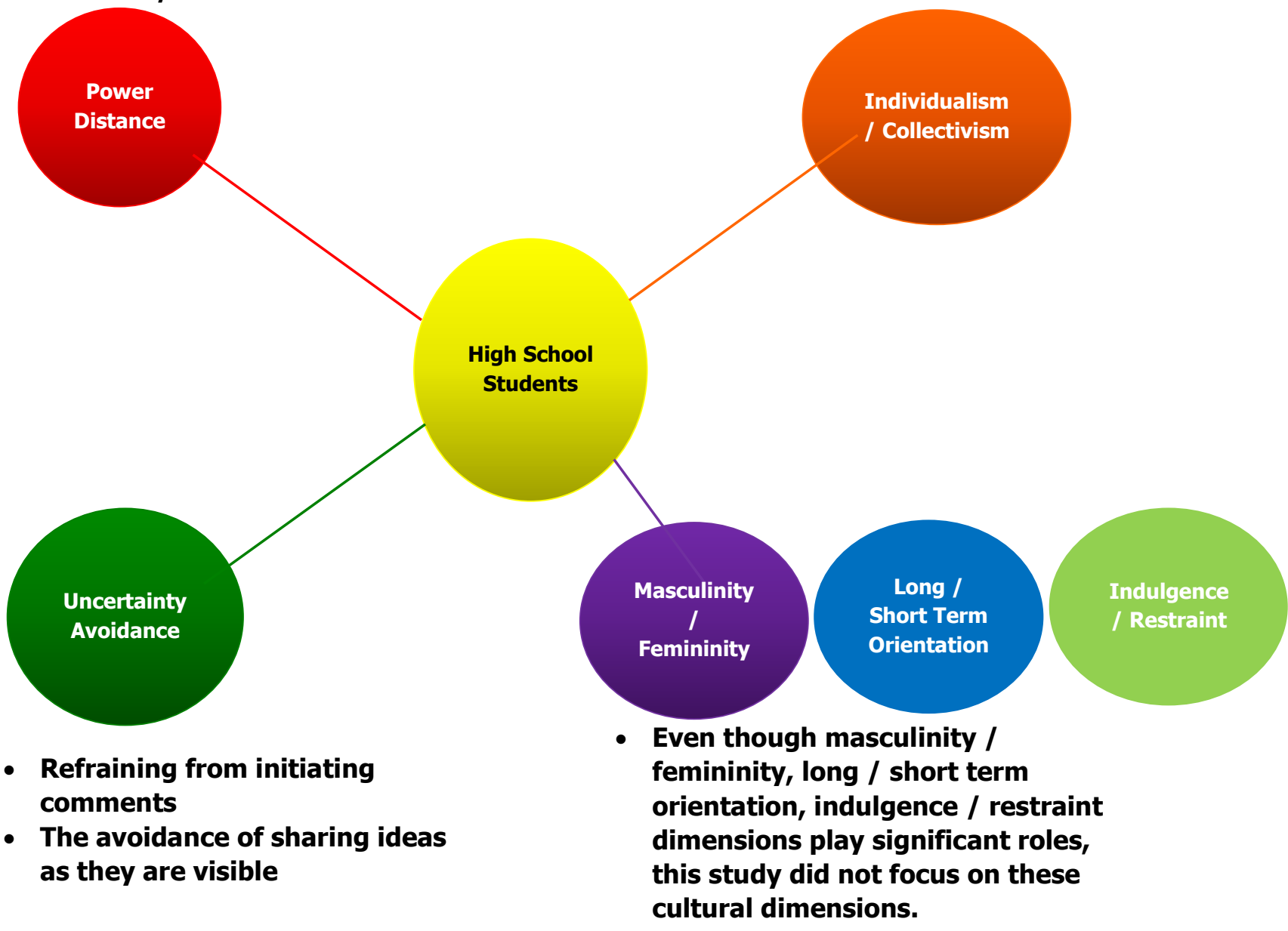

Figure 4. Participants' Insights Associated with Cultural Dimensions

\section{Online Discussion Experiences}

Twenty-eight out of 30 students stated that they benefitted from online discussion activities. At the beginning of the online discussion activities, one of the students struggled to benefit, yet later on she handled with the help of her peers and teacher. Meanwhile, there was only one student (Student 0 , Female) stated that she could not benefitted from the online discussion activities as much as her peers. Here are the quotes of students. 
vocabulary is improving as well. According to me this application is both enjoyable and instructive. We should absolutely continue in semester.

Student $O$, Female: $I$ did not participate in online discussion activities, $I$ mean I did not want to due to fact that I am a timid person. My friends shared and wrote well that made me think that I cannot write as good as them. So, I did not share or write in online discussion activities.

Student $K$, Female; $I$ think it is a very efficient and useful application for us. Because while we are discussing a topic here, we can also see the different viewpoints. We should definitely continue the semester as well. Both we see different viewpoints and improve on writing in English. It is certainly my opinion, but we can talk more about social issues.

\section{Self-expressing in Online Learning Environment}

Twenty-three students stated that they had no problem or difficulty in expressing their opinions clearly and comfortably. Meanwhile, there was one student (Student B, Female) struggling to express her ideas initially, but later stated that she was able to share or write down her thoughts with the help of her peers and teacher. Furthermore, there was only one student stated that she (Student 0 , Female) could not express herself in environments circled with crowded people, hence hindered her to share in online learning environment. Along with self-expressing skills, twenty-one students stated that they found it safe to share their opinions in online learning environment due to the fact that they know each other since they were in the same class and their teacher was also there. Here are the quotes of students.

Student B, Female: Initially, I struggled to share my opinions in online learning environment. Later on $I$ realized that $I$ can post my thoughts in which my peers and my teacher helped me. I recognized an online learning environment where we can brainstorm. I had no difficulty or problems concerning security issues as I enrolled.

Student $C$, Female: I find this online learning environment safe. I have difficulty in expressing my thoughts in face-to-face setting in the classroom, yet EDMODO enabled me to both exchange ideas with my peers and enhanced my writing skills.

Student $F$, Male: I tried to express my own feelings and thoughts clearly and had not any barrier in doing so. This online learning environment was restricted to people that you know which enables to share safely.

Student $H$, Female: I clearly expressed any idea that I wanted to and I found this online learning environment safe. Because, one can enroll with the approval of the teacher and no one other than your classroom could see your posts.

\section{Teacher and Instructor Participation}

Twenty-seven students reported that they had positive perception toward the participation of their English language teacher, and they found the participation of their teacher as a source of motivation to participate more to online discussion activities. Furthermore, twenty-eight students reported that they appreciated the participation of an instructor that they do not know and see before. They highly valued the feedback that they got from the instructor. One of the students (Student $R$, Male) reporting that his teacher did not participated adequately by justifying with his lack of time to participate, and suggested that the instructor must participate more. Finally, there was a student expressing frustration because of a lack of guidance of the teacher (Student $L$, Male). Here are the quotes of students. 
Student L, Male: I have no doubt concerning my English language teacher's proficiency, but he did not provide feedback to every student or he did not fully state his viewpoint. The reason might be the number of students enrolled in online learning environment, I do not know, but I felt bad when he did not provide me with feedback as I think that my comment is not valuable. I need my teacher's thoughts and comments. I wish he could provide his own thoughts on each and every students' posts. But I think he did not act in this way on purpose.

Student T, Female: For saying truth, this application is beneficial for me. Because I can apply special words here. I can talk with classmates and I can develop my thinks. There are two perfect teacher for us and this is so important. I mean that when someone here for helping you, this is really good thing.

Student M, Male: I think the teacher participation was quite good as he highlighted interesting posts and posted different spectrum of viewpoints which made me feel that I am under surveillance of my teacher. The more our teacher participated in online discussion activities, the more students participated, as well.

Enablers / Barriers of Participation in Online Discussion Activities

Students reported numerous enablers and / or barriers for their participation to online discussions. On one hand, the participation of foreigners to online discussions, more engaging activities and discussion topics or grading of discussion sessions were reported as enablers of a more participatory activities in online learning environment. On the other hand, access to technological resources and the internet, the anxiety of self-expressing and writing alone, the lack of interesting and engaging discussion topics, lack of appropriate time, one's shy or timid personality, the lack of self-confidence, the visibility of posts by everyone, and lack of appropriate reply or feedback were listed amongst barriers of having a more participatory online learning environment. The most fundamental concern was reported about access to technological resources, more specifically to the internet. One of the students (Student B, Female) reported that she intimidated to express her thoughts as she will be understood wrong by stating that "my fear of expressing myself wrong hindered my participation in online discussions more frequently. However, as I started to get positive comments on my posts, I realized that my fear was not as I think." One of the interesting barrier was reported by Student C (Female) about writing alone by sharing "initially, I was intimidated to express my thoughts since I felt alone, yet later on I realized that handling alone is not a barrier in which my teacher supported to overcome this barrier." Another barrier was reported by Student J (Female) concerning the language of online discussions; that is English, by stating that "since the language of discussions in online learning environment was fully English, it might be frustrating due our posts were visible and those who have not confidence with their writing directly withdraw from participating." Along with such concerns, many of the students reported that lack of interesting and engaging discussion topics was one of the pivotal barriers that hindered them time to time from participating more frequently and effectively. One of the remarkable viewpoint reported by a student (Student T, Female) was about how to have a more participatory online learning environment; that is grading those activities. She shared that "If there was a grading policy, it could be much more effective. In that way, students would try harder and more attentive to get ahead of each other."

Differences between Online and Face-to-Face Discussion Activities

Students reported numerous differences between their online and face-to-face in classroom discussions, yet one of the most prominent differences that each and every student stated is that they were expressing their feelings and opinions in a more flexible and free manner in online learning environment. Many students, particularly those feeling restrained, shy or timid during or having difficulties expressing themselves by speaking in 
classroom activities, found it easier to share their thoughts in writing than speaking. Student C (Female) reported:

In classroom settings, we express our opinions by speaking which I really have difficulty with. I cannot express my impressive thoughts by speaking. EDMODO was useful for me. If I could express my thoughts by speaking in classroom, it will be useful as much as EDMODO.

Similar concerns were reported by many of the students when they compare the differences between the online and face-to-face in classroom activities. One of the students (Student E, Female), for instance, appreciated the flexibility of online discussion and reported that "I participated in online discussion activities at home where I could think deeper and without pressure before I shared my thoughts. This is not generally possible at school." The other student (Student $\mathrm{H}$, Female) recognized that "I might sometimes become shy in classroom, yet I feel more relaxed and clearly express my ideas in online discussion." Furthermore, one of the students (Student J, Female) highlighted that "activities that are carried out in classroom settings, many of the students hold off from participating into, yet by getting help from the internet online activities become more comfortable." One of the student (Student M, Male) appreciated the equal opportunities for each student by reporting that "everyone can comment, reply on or critique each other by voicing their thoughts in online learning environment in which there is no shyness or embarrassment." One other interesting difference reported by one of the students (Student $N$, Female) is that "in classroom activities, we deprive of courage for speaking or we express our thoughts in a limited extent, yet online learning environment is a great opportunity for us. It facilitates us to voice our opinions that we cannot speak in classroom setting." The consideration of social influence was also emphasized by one of the students (Student $\mathbf{S}$, Female) in a way that " $I$ think that students in online learning environment easily transfer their opinions, because of the fact that there is no one around to be influenced." Similarly, Student $U$ (Male) also differentiated the opinions generated in classroom and at home when participating in online learning environment by stating that "ideas inspected in classroom setting might differ from those generated at home." On the contrary, Student 0 (Female) preferred in classroom activities by reporting "in classroom activities, if the teacher chooses you to complete the activity, you have to do it; which is good, however, since online learning was a free environment, I did not participated." Finally, Student S (Female) also expressed her concern for differences of both online and face-to-face in classroom discussions and shared "In classroom setting where we are constantly gazed, not confident enough to express our thoughts fully is different from online activities which enabled me to participate in at home by voicing my inner and deeper thoughts without the pressure of outer voices."

\section{DISCUSSION}

The data collected from $\mathbf{3 0}$ high school students enrolled in an online learning environment revealed the insights of learners concerning their online learning activities. The findings shed light on how students interact with the content, their peers, teacher and instructor. The findings also revealed several differences between activities that were carried out in online and face-to-face in classroom learning environment.

First of all, although there were several boundaries, the majority of the students enrolled in online learning environment stated that they benefitted from these activities. This finding is consistent with previous studies reporting that online learning might be beneficial for students' learning (e.g., Commander et al, 2016; Hamdan, 2014; Sadykova, 2014; Zhang, 2013).

Second, the findings revealed that students found it safe to express their feelings and opinions comfortably due to the fact that their peers and teacher were also there. One of the possible explanations for this finding might be associated with collectivist cultural background. In collectivist cultures, such as Turkey (Hofstede et al., 2010), students feel 
safer to voice up their opinions in smaller groups particularly where the teacher is present. Furthermore, if there are strangers or out-group members, it will get more difficult to enable student participation to activities (Hofstede et al., 2010). In fact, this finding confirms previous research on interaction patterns in online learning environment. For instance, Stepanyan, Mather, and Dalrymple (2014) investigated the interaction patterns in a multicultural online collaborative learning environment and found that there were different interaction patterns with respect to cultural differences in which those sharing the same cultural background tended to interact amongst themselves. Similarly, Lecluijze et al. (2015) investigated Dutch, Moroccan-Dutch, and Turkish-Dutch youth's online social network experiences. The study showed that Turkish-Dutch youth tended to find information and share media content primarily by engaging in their own ethnic transnational networks. This finding suggests that learners' need for the feeling of teacher and peer presence in online learning environment might change with respect to cultural background and it should be adjusted with leaners' needs. Particularly, as this study found, students might find it safer and more secure to express their feelings where in-group members; their peers and the teacher, exist possibly due to a more collectivist tendencies. Third, students highly appreciated the participation of both their English language teacher and an instructor that they do not know and see before. Furthermore, students expected higher levels of participation of their teacher and the instructor. Confirming previous studies this finding indicated that students needed guidance of their teacher and the instructor, particularly valuing the comments or feedback that they received from them, even felt that their posts were not valuable as they did not get feedback from the teacher and/or instructor. This finding is also consistent with previous studies. For instance, Nandi et al. (2012) reported that students depended highly on the feedback that they got from their instructor in online discussion. Baran (2010) found that when the teacher commented on students' postings, they felt excited. Mazzolini and Maddison (2003) found that the way instructors post in online discussion forums might have an influence on students' perceptions and discussions by arguing that different levels of instructor participation might increase or decrease students' participation. This finding suggest that the feeling of teachers' and / or instructors' presence in online learning environment is an important element. One possible explanation for this finding might be associated with large power distant cultural background. As Baran (2010) stated, students and teachers expect and accept "ascribed" behaviors and students expect to experience the knowledge and authority of the teacher regardless of the learning environment, whether it is online or face-to-face. As Turkey has a large power distant cultural background, students need for higher levels of teacher presence in online learning environment show that they might need and value teacher knowledge, authority and experience. One possible implication of this finding might be about increasing the awareness of teachers and instructors concerning cultural dynamics in online learning as they unconsciously could not recognize those patterns and needs. For instance, McDermott (2017) found that even though the faculty recognize the diverse learning needs of their students, culture was not included as a consideration either in the design or delivery processes of the online courses. In this regard, raising awareness of both students and teachers for a more culturally inclusive learning experience in online learning environment might be one of the suggestions and implications, as well.

Fourth, students also reported numerous enablers and/or barriers that influenced their active participation, such as, access to the internet, the anxiety of self-expressing and writing alone, one's shy or timid personality, the lack of self-confidence, the visibility of posts by everyone, and lack of appropriate reply or feedback from the teacher. One of the most influential barrier that the majority of the students reported that their avoidance of sharing their ideas since they are visible to everyone and the lack of self-confidence. There are two possible explanations for this finding which might be associated cultural dimensions; one of which is the collectivist and the uncertainty avoidance dimensions. According to Hofstede et al. (2010) face gaining is an important element for the structure of a classroom in a collectivist culture both for students and teachers. Furthermore, confrontations and conflicts should be avoided as not to hurt anyone and students should not lose face. While the collectivist dimension might play a role for the visibility of the posts 
by everyone and the sense of a lack of self-confidence, this situation might also be attributed to the dimension of uncertainty avoidance. Turkey has a very high uncertainty avoidance index implying that what is attributed with uncertain is to be avoided. In this regard, since participants were not familiar with online learning environment before and it is a new and different way of carrying out learning activities, it might be associated with an uncertain situation that could have an influence on their self-confidence to post and share their ideas in online learning environment. In fact, Roberts and Kanagasabai-Rajah (2013) offered a solution to overcome this barrier. They investigated the influence of anonymity on students' sharing in online discussion board and found that students were more likely to share when they were able to post anonymously. The researchers suggested that anonymous postings might be used as an alternative way to encourage a more participatory online learning environment. Such different strategies appropriate and relevant with the cultural needs of students might improve the quality of interaction in online learning environments.

Finally, students reported numerous differences between discussion activities carried out online and face-to-face. The majority of the students reported that online discussions were more flexible for them to share their ideas freely without any pressure. This finding is in line with numerous studies within the literature. For instance, Comer and Lenaghan (2012) offered that online asynchronous discussions might be more inclusive than face-to-face discussions for some students, particularly those having difficulties in classroom setting. Gunawardena (2013) stated that computer-mediated communication might equalize power and status differences in large power distance societies. In this regard, one of the possible explanations for this finding might be associated with the cultural dimension of large power distance cultural background in Turkey. The reason why students found it more comfortable to share their ideas in online learning environment is that the teacher in classroom discussion activities have a large power in which students intimidate to challenge their teachers' and peers' ideas to avoid conflict and disagreement. In large power distant classrooms, teachers are not contradicted or criticized and they are treated with deference even outside the school (Hofstede et al., 2010). Hence, the online learning environment facilitated students to have the opportunity of expressing their ideas more freely; that is, without the pressure of their peers and the teacher. This might also be attributed to the lessened power asymmetries in online learning environment as stated by Zhang (2013). Thanks to a more egalitarian distribution of power in online learning environment, students might found it to voice their minds more comfortably in a lessened pressure from the peers and the teacher.

\section{CONCLUSION}

From a qualitative pattern, this study investigated the insights and experiences of high school students' in an online learning environment. The study revealed participants' insights particularly by associating them with cultural dimensions proposed by Hofstede et al. (2010). The study provided evidence that online learning environment is beneficial for students learning. However, several concerns regarding the reciprocal interaction between students, teacher and instructor were also revealed which are highly attributable to cultural aspects.

There are two primary implications of this study for future research; (1) designing culturally inclusive online learning environment and (2) the culture of online learning environment. One possible suggestion to design and operationalize a more culturally inclusive online learning environment might be established by following numerous guidelines and frameworks as suggested within previous studies (e.g. Dreamson, Thomas, Hong, \& Kim, 2017; Rutherford \& Kerr, 2008). For instance, Rutherford and Kerr (2008) offered numerous examples of delivery beginning from low degree of cultural inclusivity to high degree of cultural inclusivity. Second and one of the most significant implications is about the culture of online learning which is generally "at odds with local cultures and contexts" (McDermott, 2017, p. 3113). The focus of online learning depends on Western / Anglo approach in which the values of "independence, low power distance, acceptance of risk and 
low context" are forefront (Goodfellow \& Lamy, 2009, p.6) which contradicts with the cultural values of Turkey in which interdependence, large power distance, high uncertainty avoidance and high context cultural background exist (e.g. Baran, 2010; Erdem, 2006; Erdem \& Günlü, 2008, Hofstede et al., 2010). In this regard, it is important to distinguish the local culture from the affordances of technology as it is not the artifact that is accessible and available but "how the members of the group interpret, use, and perceive them" (as cited in McDermott, 2017, p. 3112). In this regard, deciding on whether online learning environment is appropriate and relevant to empower students' learning above and beyond Western cultural dispositions is an important consideration to be taken into account. For instance, if online learning environment is perceived as a more egalitarian space in which students voice up their minds more comfortably compared to face-to-face classroom setting, is it still valuable within local cultural setting? Or what it means when teachers, instructors and researchers uphold with "relentless imposition of Western values" (Yang, 2003, p. 282) to empower student learning even though those values misfit with both the students and their own cultural niches. Such considerations are still elusive that needs further and deeper investigations.

Along with numerous implications, the findings might provide teachers, scholars and instructional designers with a better understanding for how cultural aspects might influence students' learning in online learning environment. This study contributed to the currently limited understanding of how culture could play a significant role in designing and operationalizing online learning environments, as well as provided evidence to the existing literature on culture and online learning. Future studies might focus on cultural dimensions at individual basis rather than the national one, along with specifically focusing on one cultural dimension. Furthermore, cultural dimensions at the individual level should be examined with respect to gender differences as they might be perceived differently at individual level. The interaction patterns between the teacher and students during the operationalization of online learning could be adjusted with respect to different cultural backgrounds as students from collectivist cultures might need more interaction and guidance in faceless learning environment. Finally, as Reinecke and Bernstein (2013) suggested rather than operationalizing already available online learning environments, culturally adaptive learning interfaces could be designed, developed and implemented to empower students' learning.

\title{
BIODATA and CONTACT ADDRESSES of AUTHORS
}

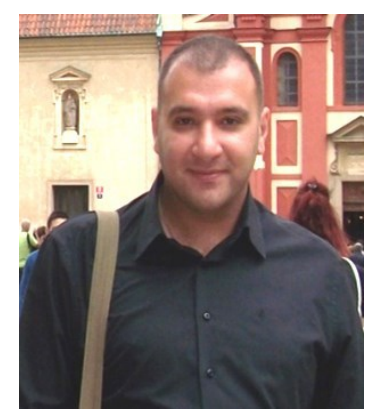

Dr. Salih BARDAKCI is an Assistant Professor of Computer Education \& Instructional Technology at Faculty of Education, Tokat Gaziosmanpasa University. Dr. Bardakci gained his Ph.D. in Educational Technology on December, 2013. His academic interests are information and communication technologies (ICT) in education, socio-cultural aspects of online learning environments, ICT ethics, institutionalization of educational technology field, and teacher education.

\author{
Dr. Salih BARDAKCI \\ Department of Computer Education \& Instructional Technology \\ Faculty of Education, Gaziosmanpasa University, 60250, Tokat, Turkey. \\ Phone: $+903562521616-3532$, \\ E-mail: salih.bardakci@gop.edu.tr
}




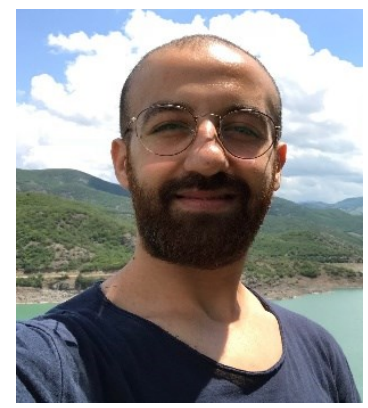

Omer ARSLAN is a graduate assistant at Instructional Systems \& Learning Technologies, Florida State University, Tallahassee, the U.S.A. His main research interests are online learning environments, technology integration into education, culture and learning, and interaction in learning environments.

Omer ARSLAN

Instructional Systems \& Learning Technologies

Florida State University

Stone Building, Tallahassee, Florida, 32306-4450, the U.S.A.

E-mail: oa18h@my.fsu.edu

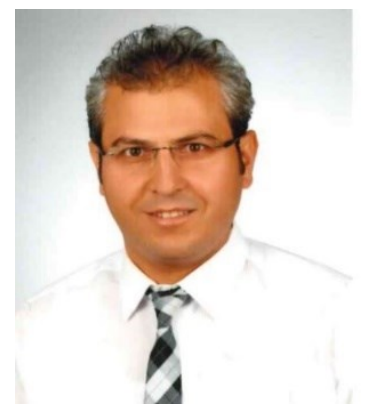

Yafes CAN is an English Teacher at Yenisehir Anatolian High School in Sivas, Turkey and a postgraduate student at department of curriculum and instruction at Anadolu University in Eskisehir, Turkey. His main research interests are emotions in teaching environment, ICT integration into education, teaching language and curriculums.

\section{Yafes CAN}

Department of Curriculum and Instruction, Education Faculty

Anadolu University

26210, Eskisehir, Turkey

Phone: +90 5435635048

E-mail: yafescan@gmail.com

\section{REFERENCES}

Baran, B. (2010). Facebook as a formal instructional environment. British Journal of Educational Technology. 41(6), E146-E149.

Bing, W., \& Ping, T. A. (2008). A comparative analysis of learners' interaction in the online learning management systems: Does national culture matter? Asian Association of Open Universities Journal, 3(1), 1-16.

Bloor, M., \& Wood, F. (2006). Keywords in qualitative methods: A vocabulary of research concepts. London: Sage Publications.

Boeri, N. (2016). Technology and society as embedded: an alternative framework for information and communication technology and development. Media, Culture \& Society, 38(1), 107-118.

Bozkurt, A., Akgun-Ozbek, E., Yilmazel, S., Erdogdu, E., Ucar, H., Guler, E., Aydin, C. H. (2015). Trends in distance education research: A content analysis of journals 2009-2013. International Review of Research in Open and Distributed Learning, 16(1), 330-363.

Chen, R. T., \& Bennett, S. (2012). When Chinese learners meet constructivist pedagogy online. Higher Education, 64(5), 677-691. 
Comer, D. R., \& Lenaghan, J. A. (2012). Enhancing discussions in the asynchronous online classroom: the lack of face-to-face interaction does not lessen the lesson. Journal of Management Education, 37(2), 261-294.

Commander, N., Zhao, Y., Gallagher, P., \& You, Y. (2016). Cross-national online discussions: International learning experiences with American and Chinese students in higher education. Innovations in Education and Teaching International, 53(4), 365-374.

Cronje, J. C. (2011). Using Hofstede's cultural dimensions to interpret cross-cultural blended teaching and learning. Computers \& Education, 56(3), 596-603.

Çetin, S., Ellidokuzoglu, H., \& Dogan, S. (2014). Teacher-student relationships across teaching careers of Turkish EFL teachers. Educational Research and Reviews, 9(20), 1037-1045.

Dennehy, E. (2015). Learning approaches and cultural influences: A comparative study of Confucian and Western-heritage students. Journal of Further and Higher Education, 39(6), 818-838.

Dreamson, N., Thomas, G., Hong, A. L., \& Kim, S. (2017). Policies on and practices of cultural inclusivity in learning management systems: perspectives of Indigenous holistic pedagogies. Higher Education Research \& Development, 36(5), 947-961.

Erdem, R. (2006). Evaluating of communication preferences with differences of highcontext and low-context: Developing a Turkish scale. Firat Saglık Hizmetleri Dergisi, 1(2), 17-25.

Erdem, R., \& Günlü, E. (2008). An analysis of communication tendencies according to the high and low context distinction: A case of hospital employees. Hacettepe Journal of Health Administration, $9(2), 177-195$.

Fraenkel, J. R., \& Wallen, N. E. (2006). How to design and evaluate research in education ( $\sigma^{\text {th }}$ edition). New York: The McGraw-Hill. Sixth Edition.

Frisby, B. N., Slone, A. R., \& Bengu, E. (2016). Rapport, motivation, participation, and perceptions of learning in U.S. and Turkish classrooms: A replication and cultural comparison. Communication Education, 66(2), 183-195.

Germain-Rutherford, A. G., \& Kerr, B. (2008). An inclusive approach to online learning environments: Models and resources. Turkish Online Journal of Distance Education, 9(2), 64-85.

Goodfellow, R. \& Lamy, M.-N. (2009). Conclusion: Directions for Research in Online Learning Cultures. In Goodfellow, Robin and Lamy, Marie-Noelle eds. Learning Cultures in Online Education. Continuum Studies in Education. London: Continuum Books, pp. 170-183.

Graneheim, U. H., \& Lundman, B. (2004). Qualitative content analysis in nursing research: concepts, procedures and measures to achieve trustworthiness. Nurse Education Today, 24(2), 105-112.

Gunawardena, C. N. (2013). Culture and online distance learning. In M. G. Moore (Ed.), Handbook of Distance Education (pp. 185-200). New York, NY: Routledge.

Hamdan, A. K. (2014). The reciprocal and correlative relationship between learning culture and online education: A case from Saudi Arabia. The International Review of Research in Open and Distributed Learning, 15(1), 309-336.

Hofstede, G. (1983). National cultures in four dimensions: A research based theory of cultural differences among nations. International Studies of Management \& Organization, 13(1-2), 46-74.

Hofstede, G. (1986). Cultural differences in teaching and learning. International Journal of intercultural relations, 10(3), 301-320. 
Hofstede, G., Hofstede, G. J., \& Minkov, M. (2010). Cultures and organizations: Software of the mind: Intercultural cooperation and its importance for survival. McGraw Hill.

Hofstede, G. (2011). Dimensionalizing cultures: The Hofstede model in context. Online Readings in Psychology and Culture, 2(1), 1-26.

Jayatilleke, B. G., \& Gunawardena, C. (2016). Cultural perceptions of online learning: Transnational faculty perspectives. Asian Association of Open Universities Journal, 11(1), 50-63.

Joy, S., \& Kolb, D. A. (2009). Are there cultural differences in learning styles? International Journal of Intercultural Relations, 33(1), 69-85.

Kang, H., \& Chang, B. (2016). Examining culture's impact on the learning behaviors of international students from Confucius culture studying in Western online learning context. Journal of International Students, 6(3), 779-797.

Lecluijze, S. E., de Haan, M., \& Ünlüsoy, A. (2015). What online networks offer: Online network compositions and online learning experiences of three ethnic groups. International Journal of Higher Education, 4(3), 68-81.

Liu, X., Liu, S., Lee, S., \& Magjuka, R. J. (2010). Cultural differences in online learning: International student perceptions. Educational Technology \& Society, 13(3), 177188.

Mansson, D. H., \& Lee H. B. (2014). American and South Korean engineering students' communication motives and their student-instructor communication satisfaction. Journal of Intercultural Communication Research, 43(1), 30-44.

Mazzolini, M. \& Maddison, S. (2003). Sage, guide, or ghost? The effect of instructor intervention on student participation in online discussion forums. Computers \& Education, 40(3), 237-253.

McDermott, G. (2017). Towards a culturally responsive pedagogy in online teaching: An Irish perspective. All Ireland Journal of Teaching and Learning in Higher Education, 9(3), 3111-31119.

Minkov, M., \& Hofstede, G. (2012). Is national culture a meaningful concept? Cultural values delineate homogeneous national clusters of in-country regions. CrossCultural Research, 46(2), 133-159.

Nandi, D., Hamilton, M., Chang, S., Balbo, S. (2012). Evaluating quality in online asynchronous interactions between students and discussion facilitators. Australasian Journal of Educational Technology, 28(4), 684-702.

Reinecke, K., \& Bernstein, A. (2013). Knowing what a user likes: A design science approach to interfaces that automatically adapt to culture. MIS Quarterly, 37(2), 427-453.

Roberts, L. D., \& Kanagasabai-Rajah, C. J. (2013). "I'd be so much more comfortable posting anonymously": Identified versus anonymous participation in student discussion boards. Australasian Journal of Educational Technology, 29(5), 612624.

Roblyer, M. D., \& Wiencke, W. R. (2003). Design and use of a rubric to assess and encourage interactive qualities in distance courses. American Journal of Distance Education, 17(2), 77-98.

Sadykova, G. (2014). Mediating knowledge through peer-to-peer interaction in a multicultural online learning environment: A case study of international students in the US. The International Review of Research in Open and Distributed Learning, 15(3), 24-49.

Salmon, G. (2002). E-tivities: The key to active online learning. London: Kogan Page. 
Sanchez, I., \& Gunawardena, C. N. (1998). Understanding and supporting the culturally diverse distance learner. In C.C. Gibson, (Ed.), Distance learners in higher education (pp. 47-64). Madison, WI: Atwood Publishing.

Selwyn, N. (2016). Is technology good for education? Polity Press, UK.

Stepanyan, K., Mather, R., \& Dalrymple, R. (2014). Culture, role and group work: A social network analysis perspective on an online collaborative course. British Journal of Educational Technology, 45(4), 676-693.

Vaismoradi, M., Turunen, H., \& Bondas, T. (2013). Content analysis and thematic analysis: Implications for conducting a qualitative descriptive study. Nursing and Health Sciences 15(3), 398-405.

Vatrapu, R., \& Suthers, D. (2007). Culture and computers: a review of the concept of culture and implications for intercultural collaborative online learning. In Intercultural Collaboration (pp. 260-275). Springer Berlin Heidelberg.

Venkatesh, V., Thong, J. Y. L., \& Xu, X. (2016). Unified theory of acceptance and use of technology: A synthesis and the road ahead. Journal of the Association for Information Systems, 17(5), 328-376.

Westbrook, T. P. (2014). Global contexts for learning: Exploring the relationship between low-context online learning and high-context learners. Christian Higher Education, 13(4), 281-294.

Wong, Y. Y., Zeng, J., Ho, C. K. (2016). Trends in open and distance learning research: 2005 vs 2015. Asian Association of Open Universities Journal, 11(2), 216-227.

Yang, R. (2003). Globalisation and higher education development: A critical analysis. International Review of Education, 49(3-4), 269-291.

Zhang, J. (2007). A cultural look at information and communication technologies in Eastern education. Educational Technology Research and Development, 55(3), 310-314.

Zhang, Y. (2013). Power distance in online learning: Experience of Chinese learners in U.S. higher education. The International Review of Research in Open and Distributed Learning, 14(4), 238-254.

Zhang, Z., \& Kenny, R. F. (2010). Learning in an online distance education course: Experiences of three international students. International Review of Research in Open and Distance Learning, 11(1), 17-36. 


\section{APPENDIX}

\section{Qualitative Questionnaire}

Dear participant,

This study examines the insights of online learning experience. It is kindly expected that you respond to the questions listed below and state your thoughts in detail. It will take approximately $\mathbf{2 0}$ minutes to complete the questionnaire, and the data will be used only for the research purpose.

Thank you so much for devoting your valuable time to fulfil the questionnaire.

- Gender :

- Age :

- Have you ever experienced learning through online environment? :

- Do you have a smart phone? :

- Do you have internet access? :

Please explain each of the items below as much detailed as possible.

1. What do you think about online learning environment you enrolled during the course?

2. Could you state your opinion comfortably in online learning environment?

3. What do you think about the barriers that hinder you to participate in online learning activities?

4. What should happen to engage you and your peers to participate more in online learning activities?

5. What do you think about the participation of your teacher to online learning activities?

6. What do you think about the participation of an instructor to online learning activities?

7. Could you explain your feelings during your participation in online learning activities as much detailed as possible?

8. What do you think about the differences between activities carried out online learning environment and face-to-face classroom environment?

* Note that the qualitative questionnaire and participants' responses were in Turkish and language validity was not established for the English version. 